\title{
SOBRE AS RUÍNAS DE BABEL - A CONSTRUÇÃO DA TRADUÇÃO EM BORGES
}

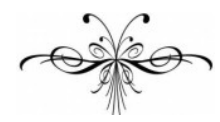

MELANIE PATRIZIA StRAsSER

Resumo: Este artigo pretende apresentar o papel da tradução e a construção da relação entre original e tradução em Jorge Luis Borges. Partindo do mito de Babel, será demonstrada a superação das suas implicações melancólicas de perda e incompletude em Borges. Através da afirmação da falácia de um texto definitivo e do caráter de rascunho de todo texto - cujo sentido não é descoberto, mas vai sendo construido -, da ilusão da suposta fidelidade do tradutor - e portanto, da dessacralização do original e da valorização da tradução enquanto força transformadora -, Borges vai desconstruir o lugar inferior tradicional da tradução em relação ao original.

Palavras-chave: Teoria da Tradução; Jorge Luis Borges; Babel; melancolia; desconstrução.

\begin{abstract}
The present paper discusses the role of translation in Jorge Luis Borges and his construction of the relation between original and translation. Starting from the myth of Babel, it will be demonstrated how Borges overcomes its melancholic implications of loss and incompleteness. By making evident the fallacy of a definitive text and that every text is a draft - whose meaning is not discovered, but constructed -, that the translator's supposed fidelity is an illusion - thus demystifying the original and valuing translation as a transformative power, Borges deconstructs the traditional inferior status of translation in relation to the original.
\end{abstract}

Keywords: Translation Studies; Jorge Luis Borges; Babel; melancholy, deconstruction. 
A "torre de Babel" não configura apenas a multiplicidade irredutível das línguas, ela exibe um não-acabamento, a impossibilidade de completar, de totalizar, de saturar, de acabar qualquer coisa que seria da ordem da edificação, da construção arquitetural, do sistema e da arquitetônica.

Jacques Derrida $^{1}$

$\mathrm{O}$ pensamento sobre tradução de Borges está irredutivelmente entretecido em toda a sua escrita: além dos tantos contos/ensaios que giram em torno de tradutores e traduções ${ }^{2}$, todo o texto borgiano está permeado por uma multiplicidade de observações, reflexões e metáforas que podem ser produtivas para (re)pensar a tradução. Sua construção textual, no entanto, não proporciona uma "teoria", ainda menos uma "metodologia”, da tradução, mas um caleidoscópio de questões que envolvem o fenômeno da tradução e que estão entrelaçadas com as questões das relações entre o texto, o autor, o leitor, a biblioteca. As referências diretas e indiretas à tradução e suas implicações, que estimulam a reflexão sobre ela, representam, portanto, um fio condutor dentro do texto-labirinto borgiano.

Em seu ensaio "Las versiones homéricas", de 1932, Borges constata: "Ningún problema tan consustancial con las letras y con su modesto misterio, como el que propone una traducción” (BORGES 1996a, 239). Nessa concepção, a tradução deixa de ser um fenômeno marginal e marginalizado: ela passa a coincidir com as letras e as questões poéticas, linguísticas, culturais, históricas e filosóficas lançadas por elas; ela torna-se um meio de reflexão sobre o ofício da escritura, a gênese de um texto, o processo de leitura. Portanto, a tradução "parece destinada a ilustrar la discusión estética” (BORGES 1996a, 239).

Em geral, pode-se constatar que durante o percurso do século $\mathrm{XX}$ vai crescendo o reconhecimento da tradução enquanto produtora de questões urgentes para os campos da literatura e da filosofia, enquanto força explosiva capaz de questionar o gesto da razão iluminista e sua lógica de exclusão através de uma suposta naturalidade de oposições hierárquicas, como as de origem e derivado, significado e significante, identidade e diferença, presença e ausência, fala e escrita, autor e leitor, original e tradução; na medida em que a tradução, enquanto experiência de diferença sui generis, evidencia o problema da representação, o processo da significação, a produção de sentido, traçando um movimento de contínua oscilação entre impossibilidade e possibilidade, ela passa a ser uma

1 Jacques Derrida: Torres de Babel. Tradução de Junia Barreto. Belo Horizonte: Editora UFMG, 2006, pp. 11-12.

2 Entre eles, destacam-se: “As duas maneiras de traduzir“, "As versões homéricas”, "Pierre Menard, autor do Quixote“, "Os tradutores das Mil e uma noites", "O imortal”, ”A procura de Averróis", "Sobre o Vathek de William Beckford", "O enigma de Edward Fitzgerald" e "Sobre The Purple Land". 
“passagem à filosofia” (DERRIDA 2005, 16). Nesse sentido, a tradução pode ser compreendida enquanto forma privilegiada de desconstrução. ${ }^{3}$

Jorge Luis Borges pode ser considerado um dos precursores desse pensamento. Na sua construção textual, a tradução é abordada como um poder capaz de subverter a concepção tradicional, binária e hierárquica da relação entre original e tradução, o que também afeta as relações entre autor e tradutor, autor e leitor, texto e leitor, respetivamente. Borges vai minando uma visão predominante no discurso sobre a tradução ao longo dos séculos, isto é, que a tradução pode apenas falhar; que é algo inevitavelmente condenado à segunda ordem, à inferioridade, algo que nunca vai cumprir o seu destino - o acabamento, a conclusão, a perfeição -, que nunca vai recuperar por inteiro a essência, o verdadeiro sentido do original, que, por sua vez, no seu caráter supostamente teológico e sagrado, permanece inatingível. Nessa visão, o tradutor, portanto, ocupa inevitavelmente um papel secundário em relação ao autor; sua tarefa é ser fiel, humilde, é submeter-se e adivinhar as intenções do autor, e transpor as mesmas para uma outra língua, para outro contexto cultural e histórico sem que essa transposição fosse perceptível. O gesto dele exigido é permanecer invisível. ${ }^{4}$

Nessa concepção, a tradução está ligada à melancolia, fenômeno que surge da carga dessa tarefa impossível de cumprir, da experiência de imperfeição e inferioridade, da busca de uma completude ilusória, da impossibilidade de um sistema, de uma totalidade. A tradução vai trazendo em si a marca de Babel, o castigo divino, o fim do entendimento, do acabamento. George Steiner descreve essa ligação da tradução com a melancolia da forma seguinte:

But the "miracle" is never complete. Each translation falls short. At best, wrote Huet $^{5}$, translation can, through cumulative self-correction, come ever nearer to the demands of the original, every tangent more closely drawn. But there can never be a total circumscription. From the perception of unending inadequacy stems a particular sadness. It haunts the history and theory of translation. "Wer übersetzt," proclaimed the German poet and pietist Matthias Claudius, "der untersetzt.” His play on words, though elementary, is untranslatable. But the image is perennial. ${ }^{6}$

3 Sobre as principais ideias da desconstrução e sua relação produtiva com a tradução ver LIMA, Érica; SISCAR, Marcos: "O decálogo da desconstrução: tradução e desconstrução na obra de Jacques Derrida”. Revista Alfa, São Paulo: UNESP, N. 44, 2000, pp. 99-112.

4 Sobre o conceito da invisibilidade do tradutor ver Lawrence Venuti: The Translator`s Invisibility. A History of Translation. London: Routledge, 1995, principalmente pp. 1-42.

${ }^{5}$ Pierre David Huet (1630-1721) foi um literato e polimato francês que dedicou parte de seu pensamento à tradução. Em 1661 publicou sua obra sobre o assunto, De Interpretatione Libri Duo, o primeiro livro intitulando-se De Optimo Genere Interpretandi e o segundo De Claris Interpretibus. Nessa obra trata de assuntos tão diversos e abrangentes quanto a natureza, a história, a teoria, o processo e a prática da tradução, defendendo uma tradução do tipo literal.

6 "Wer übersetzt, der untersetzt" é um trocadilho linguístico que joga com o contraste de significado entre os prefixos über, que significa "sobre”, "acima", "além” e unter, que significa "abaixo", "debaixo", "sob”. "Wer übersetzt" significa "Quem traduz" (übersetzen = traduzir), enquanto "untersetzt" é uma palavra inexistente em alemão, criada para a feitura do trocadilho, em que "über" é trocado por "unter". 
There is a special miseria in translation, a melancholy after Babel (STEINER 1998, 283). ${ }^{7}$

Depois de Babel, símbolo da ruptura irrevogável entre Deus e os homens, do rompimento decisivo entre as palavras e as coisas, entre o significante e o significado, jamais será possível restaurar a completude, a harmonia, a transparência da linguagem frente ao mundo; Babel é, portanto, a pedra primeira da incomensurabilidade das línguas e da impossibilidade de uma linguagem que conseguisse refletir o mundo de forma plena:

Sob sua forma primeira, quando foi dada aos homens pelo próprio Deus, a linguagem era um signo das coisas absolutamente certo e transparente, porque se lhes assemelhava. Os nomes eram depositados sobre aquilo que designavam, assim como a força está escrita no corpo do leão, a realeza no olhar da águia, como a influência dos planetas está marcada na fronte dos homens: pela forma da similitude. Essa transparência foi destruída em Babel para punição dos homens. As línguas foram separadas umas das outras e se tornaram incompatíveis, somente na medida em que antes se apagou essa semelhança com as coisas que havia sido a primeira razão de ser da linguagem. Todas as línguas que conhecemos, só as falamos agora com base nessa similitude perdida e no espaço por ela deixado vazio (FOUCAULT 2002, 52).

O trauma de Babel, portanto, repete-se em todo ato de traduzir enquanto tentativa de reunir as línguas, de refazer a consonância entre o mundo e a linguagem. A sensação de perda, de impotência, de falha, é a sombra que acompanha toda tradução. É a melancolia benjaminiana ${ }^{8}$, que surge da perda da linguagem pura, em que a palavra era o espelho da coisa, e vice-versa. A melancolia surge da inapreensibilidade daquilo que Benjamin vai chamar de Ursprache, isto é, a linguagem de origem, imediata, pura, adamítica, cuja perda é o preço que se paga pelo pecado original, pela húbris humana, e que faz com que a linguagem humana se transforme em um mero instrumento de comunicação, sem retorno ao seu caráter originário, cratilista, divino. ${ }^{9}$

7 Na tradução portuguesa: “Mas o ‘milagre’ nunca está completo. A tradução nunca alcança o alvo. Na melhor das hipóteses, escreveu Huet, a tradução pode, por meio de autocorreção cumulativa, vir sempre se aproximando das exigências do original, vir traçando tangentes cada vez mais próximas. Mas não pode nunca haver uma delimitação total. Da consciência da inesgotável inadequação brota uma particular tristeza. Ela assombra a história e a teoria da tradução. 'Wer uebersetzt', proclamou o poeta e pietista alemão Matthias Claudius, 'der untersetzt'. Seu jogo de palavras, embora elementar, é intraduzível. Mas a imagem é perene. Há uma miséria especial da tradução, uma melancolia pósBabel.” In: Steiner, George: Depois de Babel. Questões de linguagem e tradução. Tradução de Carlos Alberto Faraco. Curitiba: Editora da UFPR, 2005, p. 290.

8 Quanto à relação entre melancolia e tradução em Walter Benjamin, ver Susana Kampff Lages: Walter Benjamin. Tradução e Melancolia. São Paulo: Editora da Universidade de São Paulo, 2002.

9 Cf. Walter Benjamin: "Über Sprache überhaupt und über die Sprache des Menschen“. In: Gesammelte Schriften. Vol. II. 1. Frankfurt am Main: Suhrkamp, 1991, pp. 140-157. Ver também Pensky, Max: Melancholy dialectics: Walter Benjamin and the play of mourning. Amherst: University of Massachusetts Press, 1993. 
Apesar de a tradução surgir sobre as ruínas de Babel, essas constituem ao mesmo tempo a primeira pedra da visão da tradução enquanto impossibilidade. É essa aporia aparentemente insuperável da simultaneidade de possibilidade e impossibilidade, que desde sempre atravessa o discurso sobre a tradução.

Borges, no entanto, vai repudiar o gesto melancólico pós-babélico e destacar os ganhos em vez das perdas da tradução, sua potência em vez de sua abnegação. Pois a tese de que depois de Babel é impossível recuperar totalmente o sentido, pressupõe que existe uma essência do significado no texto original; o fundamento da tese da impossibilidade da tradução consiste na concepção da tradução enquanto processo mecânico de transmissão de significados estáveis e fixos.

No entanto, se supormos que não existe esse sentido inato, inerente ao texto, que o tradutor deveria detectar, preservar e reanimar em outra língua, vem à luz o espaço para uma visão da tradução que está aberta à multiplicidade de possibilidades de atribuição de significados, à riqueza de interpretações diferentes. Assim, vai surgir uma biblioteca em vez de um livro intocável e sagrado. O que nos ensina Borges é que a instabilidade do texto e a negação de uma relação determinista entre original e tradução, a proposta que o sentido não é descoberto, mas vai sendo construído, não nos condena ao silêncio, à mudez. A instabilidade do texto não evoca a renúncia frente à tarefa do tradutor, mas, pelo contrário, é a condição da possibilidade da tradução.

Décadas antes do advento do chamado pós-estruturalismo, Borges desconstrói a relação entre original e tradução, autor e leitor, demonstrando a necessária fragilidade e instabilidade de toda construção textual. Em 1932, Borges escreve:

Bertrand Russell define un objeto externo como un sistema circular, irradiante, de impresiones posibles; lo mismo puede aseverarse de un texto, dadas las repercusiones incalculables de lo verbal. Un parcial y precioso documento de las vicisitudes que sufre queda en sus traducciones. ¿Qué son las muchas de la Ilíada de Chapman a Magnien sino diversas perspectivas de un hecho móvil, sino un largo sorteo experimental de omisiones y de énfasis? (No hay esencial necesidad de cambiar de idioma, ese deliberado juego de la atención no es imposible dentro de una misma literatura.) Presuponer que toda recombinación de elementos es obligatoriamente inferior a su original, es presuponer que el borrador 9 es obligatoriamente inferior al borrador $\mathrm{H}$ - ya que no puede haber sino borradores. El concepto de texto definitivo no corresponde sino a la religión o al cansancio (BORGES 1996a, 239).

A noção de um texto definitivo, isto é, um texto que possui um significado inerente, inato, imóvel, único, em muda concordância com seu significante, está, portanto, ligada a uma concepção teológica, babélica. A ligação ao cansaço corresponde à renúncia da tarefa de entrar no espaço da linguagem com as suas várias interpretações possíveis, à renúncia frente ao saber que o signo absoluto é impossível de ser detectado. Porém, se a relação entre os textos é um continuum, sendo todo texto a resposta a outros, uma reescrita, uma recombinação, sem origem definível, se todo texto é móvel, aberto e sujeito a “repercussões incalculáveis”, se 
todo texto é, portanto, um “esboço”, não se pode mais manter a hierarquia entre original e tradução - "la inferioridad de las traducciones", como indica Borges, é uma “superstición” (BORGES 1996a, 239), e o original enquanto texto definitivo vira ilusão. ${ }^{10}$

As diferentes traduções de um texto produzidas ao longo do tempo são as testemunhas das mudanças às quais todo texto está sujeito, nas palavras de Borges, "un largo sorteo experimental de omisiones y de énfasis", uma "recombinación de elementos", das “vicissitudes” (BORGES 1996a, 239) das interpretações, das suas específicas circunstâncias de produção. Se houvesse um texto definitivo, não existiria aquele grande leque de interpretações tão admirado por Borges, sua biblioteca universal que nasce da variedade das traduções, formando uma grande "riqueza heterogénea e hasta contradictoria” (BORGES 1996a, 240).

A estrutura da linguagem em geral, sua textualidade, consiste em seu caráter de rascunho, de descentramento, de provisoriedade. Nesse tecido sem centro, sem entidade divina que garanta o sentido, todo texto é necessariamente um esboço. Consequentemente, o texto definitivo, ou seja, o original, não pode mais reclamar seu papel de origem única, de significado estável e fixo, mas passa a ser uma resposta a outros textos, que, por sua vez, são respostas, e assim por diante. Ou, como Octavio Paz afirma:

Cada texto es único y, simultáneamente, es la traduccíon del otro texto. Ningún texto es enteramente original porque el lenguaje mismo, en su esencia, es ya una traducción: primero, del mundo no-verbal y, después, porque cada signo y cada frase es la traducción de otro signo y de otra frase. Pero eso razonamiento puede invertirse sin perder validez: todos los textos son originales porque cada traducción es distinta. Cada traducción es, hasta cierto punto, una invención y así constituye un texto único (PAZ 1971, 12-13).

Essa dessacralização do original, o desmascaramento da sua inviolabilidade faz com que a tradução saia do seu estado inferior, faz com que seja livrada das suas conotações de fracasso e derrota. A força da tradução consiste em revelar que todo texto é incalculável, algo que não se deixa fixar, mas que oscila segundo o pano de fundo dos tempos, da história. Portanto, essa visão da tradução enquanto forma de leitura, enquanto forma privilegiada de desconstrução da suposta existência de um sentido estável, não se restringe ao espaço entre duas

10 Cf. Waisman, Sergio: Borges and Translation. The Irreverence of the Periphery. Lewisburgh, PA: Bucknell University Press, 2005, pp. 50-51. Em relação ao impacto da concepção borgiana para a literatura, a crítica literária e o discurso filosófico, Waisman afirma: "In the case of Borges, the idea that the "definitive text" is a fallacy will become a key aspect of the intertextual system of quotations, citations, and allusions, both veridical and apocryphal, found throughout his fictions. Furthermore, it is in part this problematizing of originality, this idea of literature as a constant reworking of previous texts, that has appealed so strongly to poststructuralist theorists (such as Foucault, Barthes, Blanchot, and Genette) and left such a strong mark on contemporary literature (from Italo Calvino to Thomas Pynchon, among others).”, p. 51. - Poder-se-ia acrescentar que a proximidade da concepção de Borges, refletida literariamente na sua construção arquitetônica da biblioteca de Babel, com estruturas abertas tais como, por exemplo, a intertextualidade (Bakhtin, Barthes, Kristeva), a différance de Derrida ou o rizoma de Deleuze e Guattari, é notável. 
línguas diferentes. Como afirma Rosemary Arrojo, o parentesco entre tradução e leitura revela que "todo e qualquer significado [está] à mercê desse problema insolúvel e desse 'escândalo' que é a prescrição de se manter o sentido, mesmo quando se mudam a forma, a história e as circunstâncias que cercam esse sentido" (ARROJO 1993a, 55).

Toda leitura é afetada pelo problema de como manter o sentido, que sobressai até dentro da "mesma" língua. Consequentemente, segundo Arrojo, a tradução pode ser considerada um "paradigma de linguagem": todo ato de escrever, de falar, de ler, traz em si "essa estrutura babélica, essa 'confusão' primordial, essa impossibilidade de se pregar para sempre um significado a um significante" (ARROJO 1993a, 56).

Em seu ensaio "Las dos maneras de traducir", de 1926, Borges demonstra isso com base em paráfrases intralinguais:

\begin{abstract}
A veces, el traductor aprovecha los descuidos o los idiotismos del texto para verle comparaciones. Este juego, bien podría hacerse dentro de una misma literatura. ¿A qué pasar de un idioma a otro? Es sabido que el Martín Fierro empieza con estas rituales palabras: "Aquí me pongo a cantar - al compás de la vigüela." Traduzcamos con prolija literalidad: "En el mismo lugar donde me encuentro, estoy empezando a cantar con guitarra" y con altisonante perífrasis: "Aquí, en la fraternidad de mi guitarra, empiezo a cantar" y armemos luego una documentada polémica para averiguar cuál de las dos versiones es peor. La primera, ¡tan ridícula y cachacienta!, es casi literal (BORGES 1997, 259).
\end{abstract}

Nesse texto, Borges antecipa o que vai demonstrar mais tarde, e de forma tão insistente, através da experiência de sua personagem Pierre Menard: que uma tradução verdadeiramente fiel é ilusória, impossível. Como Borges mostra nesse trecho, esse "jogo" de traduzir de maneira rigorosamente literal, com a pretensão de ser absolutamente fiel, fracassa até mesmo dentro da "mesma" língua. A literalidade, portanto, sacrifica a qualidade literária do original e pode se tornar até "ridícula". Para Borges, a tradução literal ainda se encontra ligada à palavra sagrada de Deus: "How did literal translations begin? I do not think they came out of scholarship; I do not think they came out of scruples. I think they had a theological origin” (BORGES 2000, 72). Sendo qualquer tradução uma reescrita, a tradução literal, com sua carga teológica e com seu gesto de transposição mecânica, cuja pretensão é a fidelidade, situa-se, consequentemente, dentro do paradigma da impossibilidade da tradução, até mesmo na esfera intralingual. Como a tradução aparentemente fiel não pode cumprir seu objetivo, também já não é possível determinar critérios objetivos para avaliar qual tradução é a mais fiel. O conceito da fidelidade enquanto critério de avaliação torna-se obsoleto. No que diz respeito às várias traduções feitas da Odisseia, Borges constata: “¿Cuál de esas muchas traducciones es fiel?, querrá saber tal vez mi lector. Repito que ninguna o que todas“ (BORGES 1996a, 243). A impossibilidade de determinar objetivamente qual versão de uma tradução é fiel ou não, deve-se, como afirma Borges em relação às traduções homéricas, à "dificultad categórica de saber lo que pertenece al poeta y lo que pertenece al lenguaje” (BORGES 1996a, 240), de demarcar a fronteira entre o texto e o contexto, o autor e o leitor. Porém, para Borges é uma dificuldade feliz, e 
a "esa dificultad feliz debemos la posibilidad de tantas versiones, todas sinceras, genuinas y divergentes” (BORGES 1996a, 240). ${ }^{11}$ É a dificuldade, a incerteza, que abre espaço para o poder criador da tradução. Assim, a tradução torna-se a dinamite na suposta solidez e monumentalidade do original:

El Quijote, debido a mi ejercicio congénito del español, es un monumento uniforme, sin otras variaciones que las deparadas por el editor, el encuadernador y el cajista; la Odisea, gracias a mi oportuno desconocimiento del griego, es una librería internacional de obras en prosa y verso, desde los pareados de Chapman hasta la Authorized Version de Andrew Lang o el drama clásico francés de Bérard o la saga vigorosa de Morris o la irónica novela burguesa de Samuel Butler. Abundo en la mención de nombres ingleses, porque las letras de Inglaterra siempre intimaron con esa epopeya del mar, y la serie de sus versiones de la Odisea bastaría para ilustrar su curso de siglos (BORGES 1996a, 239-240).

Para Borges, portanto, as várias traduções enquanto formas de ressignificação e recriação de uma obra, enriquecem essa obra. Repudiando uma perspectiva monumental, hierárquica, arquimédica e ahistórica, como se houvesse uma interpretação correta, um significado incorruptível, elas proporcionam uma multiplicidade de leituras, de facetas e abordagens interpretativas. A Odisseia não é apenas o texto escrito por Homero no século VII a.C., mas é a diversidade de traduções, leituras e comentários. Neste ponto, Borges está muito próximo ao seu contemporâneo Walter Benjamin: as variantes de uma obra garantem sua continuação, o seu Überleben, o seu Fortleben, a sua sobrevivência, a sua pervivência, através da transformação, do desdobramento histórico do texto original. ${ }^{12}$ A tradução não é a morte do original, mas estabelece uma "conexão de vida” (BENJAMIN 2010, 207) com ele. A traduzibilidade das obras, em Borges assim como em Benjamin, deve-se a essa relação aberta, dinâmica, transformadora da tradução para com o original.

Essa transformação que a tradução implica e provoca é irreduzível. Num dos seus gestos mais notáveis, através do seu conto "Pierre Menard, autor del Quijote” (BORGES 1996b), Borges demonstra que até mesmo a tradução que parece ser a mais fiel, a que reproduz o original de maneira supostamente idêntica, é sujeita a vicissitudes: o projeto de tradução, a chamada “obra invisível” de Pierre Menard, fictício homem de letras francês do século XX, é reescrever a obra-prima de Cervantes, o Dom Quixote, imergir-se tanto nesse texto até poder recriá-lo completamente, colocando-se no lugar do autor, "ser Miguel de Cervantes" (BORGES 1996b, 447).

11 Ver também Waisman, Sergio: Borges and Translation. The Irreverence of the Periphery. Lewisburgh, PA: Bucknell University Press, 2005, pp. 53-54.

12 Cf. Walter Benjamin: "Pois na sua pervivência [Fortleben] (que não mereceria tal nome, se não fosse transformação e renovação de tudo aquilo que vive), o original se modifica. Existe uma maturação póstuma mesmo das palavras que já se fixaram. “ In: “A tarefa do tradutor". Tradução de Susana Kampff Lages. In: Heidermann, Werner (Org.): Clássicos da Teoria da Traducão. Antologia bilíngue: alemão-português. Florianópolis: UFSC/Núcleo de Pesquisas em Literatura e Tradução, 2010, p. 211. 
No quería componer otro Quijote - lo cual es fácil - sino el Quijote. Inútil agregar que no encaró nunca una transcripción mecánica del original; no se proponía copiarlo. Su admirable ambición era producir unas páginas que coincidieran palabra por palabra y línea por línea con las de Miguel de Cervantes (BORGES 1996b, 446).

Pierre Menard, a encarnação da fidelidade textual, falha, entretanto, de forma heroica: embora ele chegue a uma versão idêntica a do original, a sua tradução supostamente fiel transforma-se em algo diferente:

El texto de Cervantes y el de Menard son verbalmente idénticos, pero el segundo es casi infinitamente más rico. (Más ambiguo, dirán sus detractores; pero la ambigüedad es una riqueza.) Es una revelación cotejar el Don Quijote de Menard con el de Cervantes. Éste, por ejemplo, escribió (Don Quijote, primera parte, noveno capítulo):

... la verdad, cuya madre es la historia, émula del tiempo, depósito de las acciones, testigo de lo pasado, ejemplo y aviso de lo presente, advertencia de lo por venir.

Redactada en el siglo diecisiete, redactada por el "ingenio lego" Cervantes, esa enumeración es un mero elogio retórico de la historia. Menard, en cambio, escribe:

... la verdad, cuya madre es la historia, émula del tiempo, depósito de las acciones, testigo de lo pasado, ejemplo y aviso de lo presente, advertencia de lo por venir.

La historia, madre de la verdad; la idea es asombrosa. Menard, contemporáneo de William James, no define la historia como una indagación de la realidad sino como su origen. La verdad histórica, para él, no es lo que sucedió; es lo que juzgamos que sucedió. Las cláusulas finales — ejemplo y aviso de lo presente, advertencia de lo por venir— son descaradamente pragmáticas (BORGES 1996b, 449).

Pierre Menard, cujo objetivo é recuperar completamente o significado original, repetir exatamente o contexto histórico e social da obra de Cervantes, assim como as intenções dele, consegue apenas reproduzir as palavras. Nem a tradução aparentemente mais fiel, a cuidadosa repetição integral de uma obra na mesma língua, consegue atingir o seu objetivo de reproduzir a voz do autor. $\mathrm{O}$ significado, transposto para outro contexto histórico, muda em suas conotações, constituindo-se, portanto, através da sua diferença: Em relação ao projeto fracassado de Pierre Menard, Gilles Deleuze constata que "a mais exata repetição, a mais rigorosa repetição, tem, como correlato, o máximo de diferença” (DELEUZE 1996, 18).

O significado não existe enquanto entidade inerente ao texto, além de uma interpretação. Como não existe uma essência de sentido dentro do texto, toda leitura é uma releitura, toda tradução é uma transformação, sendo ela sempre temporária, provisória, sempre relacionada às particularidades do momento histórico. (ARROJO 1993b, 18-19) Assim, também os leitores da obra invisível de Pierre Menard atribuem vários significados diferentes à mesma: uma leitora detecta nela a influência de Nietzsche, inclusive (BORGES 1996b, 449).

"A mãe da verdade é a história”, que no conto de Borges deve ser entendido a partir do fato de que a nossa interpretação de qualquer texto é sempre 
permeada pelas nossas específicas circunstâncias históricas e sociais, por visões, convicções e ideologias, paradigmas e concepções teóricas predominantes.

Pierre Menard, no entanto, traduz apenas a mera materialidade e exterioridade, apenas as palavras, escamoteando não somente os constituintes de um texto, suas condições temporais e históricas, mas também o seu próprio lugar de enunciação. Nem mesmo Pierre Menard é neutro, passivo, transparente. Pelo contrário, ele, que "se disfarça de perseguidor fiel e ascético de originais" (ARROJO 2001, 155), afinal, está obcecado pela vontade de poder, pelo desejo de usurpar o lugar do autor, de se apropriar da obra dele. O projeto de Pierre Menard mostra que aparentemente a maior fidelidade pode ser detectada como a maior violência: pois finge não conhecer o tempo.

O "homem de letras", personagem borgiano exemplar, isolado na pretensa assepsia de sua biblioteca e preso em sua dedicação ascética ao trabalho textual, jamais poderá ser o estudioso passivo e inócuo que finge ser. Sob essa máscara, esconde a face, as armas, e sobretudo, o desejo de um lutador quixotesco, empenhado na conquista de seu invisível sonho autoral (ARROJO 1993c, 170).

A ambicionada fidelidade menardiana é impossível, o suposto lugar da fala inocente e neutro revela-se como mera quimera, como u-topos, e até "a repetição total das palavras de outrem não repete o que foi dito", mas termina sendo uma recriação devido ao fato de que o sentido, o que está dito, "nunca se agarra às palavras” (ARROJO 1993c, 165). Pierre Menard, “dividido entre o desejo de apropriação total e a intenção consciente e declarada de fidelidade total, dividido entre as exigências da consciência e as determinações do inconsciente" (ARROJO 1993c, 163), é a encarnação do tradutor ideal, utópico. O conto de Borges é uma paródia do papel tradicionalmente exigido, mas impossível de cumprir, do tradutor. Borges desmascara a ilusão da proposta invisibilidade da tarefa tradutória: o sujeito interpretante não deve mais desaparecer e buscar um impossível lugar arquimédico, mas deve afirmar a sua necessária interferência no seu universo textual.

Resumindo, o pensamento de Borges nos revela que a afirmação da impossibilidade de um texto definitivo, de significados estáveis, completos, absolutos, de uma congruência entre significante e significado, é que possibilita a tradução. A possibilidade se instaura ali onde o original é percebido na sua constituição desde já aberta. A impossibilidade, que leva a renúncia, a queda no silêncio dos hexágonos da biblioteca de Babel, reside numa visão do texto original como algo fechado, total, integral, que inclui em si o significado que jamais será atingido pelo leitor, ou seja, pelo tradutor. Uma visão determinista da linguagem, do texto, impossibilitaria a variedade de interpretações e traduções de uma obra, enquanto na visão indeterminista cabe a famosa biblioteca borgiana de Babel, aquele universo infinito (BORGES 1996c) ${ }^{13}$, sem centro (sem sentido divino), sem

13 Cf. Jorge Luis Borges: “Acabo de escribir infinita. No he interpolado ese adjetivo por una costumbre retórica; digo que no es ilógico pensar que el mundo es infinito. Quienes lo juzgan limitado, postulan que en lugares remotos los corredores y escaleras y hexágonos pueden inconcebiblemente cesar, lo cual es absurdo. Quienes la imaginan sin límites, olvidan que los tiene el número posible de libros. Yo me atrevo a insinuar esta solución del antiguo problema: La 
começo (sem origens e originais definitivos, intocáveis) e sem fim (sem respostas e traduções acabadas, termináveis).

A tarefa do sujeito que nasce dentro dessa biblioteca (que o precede), é a de falar mesmo assim, de recombinar o que desde já encontra, de criar uma nova ordem a partir de elementos já dados. É a tarefa do sujeito renunciar à mudez, não se precipitar - assim como os bibliotecários suicidários borgianos - nos buracos negros da biblioteca, os símbolos da mudez. O sujeito deve falar, mesmo sabendo da impossibilidade de um acabamento, da perfeição, mesmo sabendo que já foi tudo dito, escrito, pensado - : "La certidumbre de que todo está escrito nos anula o nos afantasma“ (BORGES 1996c, 470) - ou o sujeito se cala como consequência resignativa e perde sua constituição enquanto sujeito, ou se transforma em uma quimera na sua alucinação delirante de uma fala soberana, originária, original. "Hablar es incurrir en tautologías” (BORGES 1996c, 470). Jamais será possível produzir algo realmente novo, algo originário, que não seja uma resposta. É essa constituição paradoxal do sujeito que torna inevitável a fala dele, uma fala sempre responsiva, nunca resgatável. Para Borges, em contraposição a Walter Benjamin, essa condição irreduzível do sujeito não está ligada à melancolia, mas sim ao dizersim à vida de Nietzsche, ao dizer sim à diferença, à participação da inacabável construção do mundo.

Desta maneira, Borges afirma o valor, a validade da tradução, tirando-a do seu lugar inferior em relação ao original, destacando sua potência de continuar a vida do original, que, por sua vez, vive transformações através do processo da leitura, da tradução. Borges nega, portanto, a esquematização hierárquica tradicional entre original e tradução, demonstrando a permutabilidade dos dois elementos, pois ambos estão sujeitos à mesma estrutura textual, fato que não permite hierarquias, nem identidades, mas apenas diferenças.

No entanto, restam algumas perguntas - cujas respostas hão de ser adiadas, podem ser apenas aludidas aqui. Essa estrutura textual de diferenças e aberturas sem hierarquias não implica um nivelamento, fazendo com que tudo seja igual e indistinguível? Se toda escrita estiver sujeita à mesma textualidade, se o original e a tradução forem intercambiáveis, como será possível avaliar a qualidade de uma tradução, como será possível rejeitar uma variante e louvar a outra, como o próprio Borges faz continuamente? E quais são as consequências éticas dessa construção borgiana, de que é impossível resgatar as intenções autoriais, de que todas as diversas versões de um original têm direito de existir, de que a fidelidade é uma ilusão e toda tradução é, irredutivelmente, uma transformação, nunca capaz de captar o sentido original intencionado pelo autor? Será que não há um limite de intervenção no texto que deve ser traduzido? Como determinar o limite das marcas que o tradutor pode deixar? Como responder à violência derivada dessa construção, que proporciona tanta liberdade ao tradutor, para com um texto alheio?

biblioteca es ilimitada y periódica. Si un eterno viajero la atravesara en cualquier dirección, comprobaría al cabo de los siglos que los mismos volúmenes se repiten en el mismo desorden (que, repetido, sería un orden: el Orden).“ In: "La biblioteca de Babel“. In: Obras completas. 1923-1949. Barcelona: Emecé, 1996. pp. 470-471. 
Quanto à textualidade a que estão sujeitos original e tradução, a negação da hierarquização não implica um nivelamento, mas inaugura uma rede inesgotável de referências: é a tentativa de eludir oposições binárias tradicionais e suas consequências exclusivistas e, afinal, politicamente fatais, através da desconstrução da suposta superioridade de um dos elementos. É a tentativa de abrir um espaço em que a tradução possa ser pensada para além de um movimento linear, final, funcionalista, instrumentalista e utilitarista, em que possa ser construída enquanto processo, enquanto movimento circular $^{14}$, em que o original afeta a tradução assim como a tradução, por sua vez, afeta o original, sendo a tradução nada mais, nada menos, que uma forma de sua sobrevivência.

Quanto à questão da possível avaliação de uma tradução, Borges deixa muito claro: sem proporcionar critérios objetivos para uma avaliação, ele obviamente prefere a tradução que possui um valor próprio, isto é, uma qualidade literária, um valor estético próprio. Consequentemente, é possível preferir uma tradução a seu original, e é possível ler um original e julgar que se trata de uma má tradução. ${ }^{15}$ Consequentemente, pode até acontecer que "[o] original é infiel à tradução” (BORGES 1999, 121).

E quanto à violência? Talvez haja apenas uma resposta - uma resposta indubitavelmente provisória e insatisfatória - que a violência é irreduzível. A questão de como poder sopesá-la, quantificá-la, determinar o seu grau de permissibilidade, e o seu limite, tem de ser deixada em aberto. A linguagem em si já traz, inevitavelmente, um momento de violência devido a sua caraterística de abstração, e, portanto, todo envolvimento com um texto alheio implica uma interferência, ergo algo que nunca pode ser neutro, absolutamente fiel, livre de violência. A tarefa do tradutor, portanto, consiste na conscientização dessa violência em toda textualidade, em todo ato de falar, ler, escrever, traduzir, na aceitação que nunca pode ocupar um papel invisível, que é inevitável deixar marcas em um texto e em um mundo sobre as ruínas de Babel.

Melanie Patrizia Strasser

melanie.p.strasser@gmail.com

Mestranda, Universidade de Viena / Universidade Federal de Santa Catarina

14 Para o papel de uma concepção de um tempo circular em vez de linear na obra de Borges, ver também o conto “Las ruinas circulares” In: Obras completas. 1923-1949. Barcelona: Emecé, 1996. pp. 451-455.

15 Cf. Jorge Luis Borges: "I think that Stefan George's translation [of Baudelaire's Fleurs du mal] is perhaps better than Baudelaire's book. “ In: "Word-music and translation”. In: This Craft of Verse. Harvard University Press. Cambridge: 2000, p. 74. Ver também Jorge Luis Borges: "I read [Don Quixote] in English. When I later read Don Quixote in the original, it seemed like a bad translation to me“. In: “An autobiographical essay“. The New Yorker. 1970.

Scientia Traductionis, n.13, 2013 


\section{Referências bibliográficas}

ARrojo, Rosemary. “A tradução como paradigma dos intercâmbios intralingüísticos”. In: _ . Tradução, Desconstrução e Psicanálise. Rio de Janeiro: Imago Ed. (Biblioteca Pierre Menard), 1993a.

. "A que são fiéis tradutores e críticos de tradução? Paulo Viziolo e Nelson Ascher discutem John Donne.” In: - Tradução, Desconstrução e Psicanálise. Rio de Janeiro: Imago Ed. (Biblioteca Pierre Menard), $1993 \mathrm{~b}$. . "A tradução e o flagrante da transferência: algumas aventuras textuais com Dom Quixote e Pierre Menard”. In: _ _ Tradução, Desconstrução e Psicanálise. Rio de Janeiro: Imago Ed. (Biblioteca Pierre Menard), 1993c. . "Borges e a maldição de Babel: escritura, interpretação e conflito." In: Schwartz, Jorge (Org.): Borges no Brasil. São Paulo: Editora UNESP 2001.

BENJAMIN, Walter: "Über Sprache überhaupt und über die Sprache des Menschen“. In: Gesammelte Schriften. Vol. II. 1. Frankfurt am Main: Suhrkamp 1991.

. "A tarefa do tradutor". Tradução de Susana Kampff Lages. In: Heidermann, Werner (Org.): Clássicos da Teoria da Traducão. Antologia bilíngue: alemão-português. Florianópolis: UFSC/Núcleo de Pesquisas em Literatura e Tradução, 2010.

BoRGES, Jorge Luis: “Las versiones homéricas”. In: Obras completas. 1923-1949. Barcelona: Emecé, 1996a.

. "Las dos maneras de traducir“. In: Textos recobrados 1919-1930. Buenos Aires: Emecé Editores, 1997.

. "Pierre Menard, autor del Quijote“. In: Obras completas. 1923-1949. Barcelona: Emecé Editores España, 1996b.

. "La biblioteca de Babel“. In: Obras completas. 1923-1949. Barcelona: Emecé Editores España, 1996c.

. "Las ruinas circulares“. In: Obras completas. 1923-1949. Barcelona: Emecé Editores España, 1996d.

. "Sobre o Vathek de William Beckford”. In: Outras Inquisições. Tradução de Sérgio Molina. In: Obras completas. 1952-1972. São Paulo: Editora Globo, 1999.

. "Word-music and translation”. In: This Craft of Verse. Cambridge: Harvard University Press, 2000.

. "An autobiographical essay“. In: The New Yorker. 1970.

Deleuze, Gilles: Diferença e Repetição. Tradução de Luiz Orlandi e Roberto Machado. Rio de Janeiro: Graal, 2006.

DERRIDA, Jacques: A farmácia de Platão. Tradução de Rogério da Costa. São Paulo: Iluminuras, 2005.

. Torres de Babel. Tradução de Junia Barreto. Belo Horizonte: Editora UFMG, 2006.

FouCAult, Michel: As palavras e as coisas. Uma arqueologia das ciências humanas. Tradução de Salma Tannus Muchail. São Paulo: Martins Fontes, 2002. 
KAMPfF LAges, Susana: Walter Benjamin. Tradução e Melancolia. São Paulo: Editora da Universidade de São Paulo, 2002.

LIMA, Érica; SISCAR, Marcos: ”O decálogo da desconstrução: tradução e desconstrução na obra de Jacques Derrida”. Revista Alfa, São Paulo: UNESP, N. 44, 2000.

PAZ, Octavio: Traducción: Literatura y Literalidad. Barcelona: Tusquets, 1971.

PENSKY, Max: Melancholy dialectics: Walter Benjamin and the play of mourning. Amherst: University of Massachusetts Press, 1993.

STEINER, George: Depois de Babel: questões de linguagem e tradução. Curitiba: Editora UFPR, 2005, 533 pp. Tradução de Carlos Alberto Faraco.

VenuTI, Lawrence: The Translator's Invisibility. A History of Translation. London: Routledge, 1995.

Waisman, Sergio: Borges and Translation. The Irreverence of the Periphery. Lewisburgh, PA: Bucknell University Press, 2005. 